\title{
Reported Polio cases in Pakistan during 2019
}

\author{
Tauseef Ahmad ${ }^{1,2, *(}$, Haroon ${ }^{3}$, Taha Hussein Musa ${ }^{1,2}$, Muhammad Khan ${ }^{4}$, Mukhtiar Baig ${ }^{5}$, Feng Ning ${ }^{6}$, \\ Jin Hui ${ }^{1,2}$
}

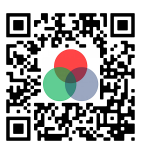

Use your smartphone to scan this QR code and download this article

${ }^{1}$ Department of Epidemiology and Health Statistics, School of Public Health, Southeast University, Nanjing (210009), China

${ }^{2}$ Key Laboratory of Environmental Medicine Engineering, Ministry of Education, School of Public Health, Southeast University, Nanjing (210009), China

${ }^{3}$ College of Life Sciences, Northwest University, Xian, China

${ }^{4}$ Department of Genetics, Centre for Human Genetics, Hazara University Mansehra, Khyber Pakhtunkhwa, Islamic Republic of Pakistan

${ }^{5}$ Medical Education and Simulation, King Abdulaziz University, Jeddah, SAU

${ }^{6}$ Chinese Centre for Disease Control and Prevention, Beijing, China

\section{Correspondence}

Tauseef Ahmad, Department of Epidemiology and Health Statistics, School of Public Health, Southeast University, Nanjing (210009), China

Email: tahmad@seu.edu.cn History

- Received: Jan 242020

- Accepted: Mar 022020

- Published: Mar 302020

DOI : 10.15419/bmrat.v7i3.596

\section{Check for updates}

\section{Copyright}

(c) Biomedpress. This is an openaccess article distributed under the terms of the Creative Commons Attribution 4.0 International license.

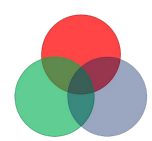

\begin{abstract}
This report describes polio cases, vaccination uncertainty and challenges, and the way forward to eradicate polio from Pakistan. Numerous articles, government and non-government documents, and survey reports were studied and an online search was made to collect information on polio in Pakistan. Once again the polio vaccination program has been stopped and accused by the local community in Pakistan as a result an increase has been seen in polio cases in the last year. In 2019, a total of 117 wild poliovirus (WPV) and 18 circulating vaccine-derived poliovirus (cVDPV2) cases were reported from the country. The majority of cases were from the Khyber Pakhtunkhwa (KP) province as a result of polio vaccination uncertainty and many challenges faced by the vaccination program in the region. Pakistan reported their highest annual number of WPV cases as compared to last few years. This increase is not only an alarming threat for the country but also a key challenge for the global polio eradication movement. Increase awareness and raising immunization to over 100\% in some areas especially in the remote area where every year many children missed vaccination to achieve global polio eradication goals.
\end{abstract}

Key words: Polio, Vaccination, Outbreak, Pakistan

\section{INTRODUCTION}

Poliomyelitis is also known as polio is a highly infectious viral disease mainly infects the children under five years of age. The virus belongs to family $P i$ cornaviridae and there are three poliovirus serotypes wild poliovirus (WPV1, WPV2 and WPV3). The virus attacks the nervous system and can cause irreversible paralysis in infected individuals in a matter of hours. The virus spreads through person-to-person contact via the fecal-oral route, contaminated food and water, even though the oral-oral route transmission is possible. The incubation period usually ranges from 7 to 21 days. The initial symptoms of the disease include fever, headache, fatigue, vomiting, pain in the limbs and stiffness in the neck. However, the majority of infected individuals (90\%) have very mild symptoms or no symptoms and usually go unrecognized ${ }^{1,2}$. Polio can be prevented through vaccination. The vaccine is given multiple times, such as the first dose of vaccine is given as early as 6 weeks of age, at 4 months of age second dose is given, at 6-18 months of age the third dose is given. However, there are 2 months recommended interval between the primary series doses. In some cases, when the protection is needed to be accelerated the minimum interval between each of the first 3 doses of inactivated polio vaccine (IPV) is 4 weeks. Hence, regardless of the number of previous doses, a dose of IPV on or after age 4 years is recommended with a minimum interval of 6 months from the next-to-last to final dose ${ }^{1}$. We aimed to describe polio cases, vaccinations uncertainty and challenges, and the way forward to eradicate polio from Pakistan.

\section{SEARCHING}

Online searches were made to collect data on polio, several government documents, survey reports and articles were studied. In addition, the World Health Organization (WHO), polio global eradication initiative and other websites were also searched.

\section{CONTEXT}

A polio eradication movement is underway and every year a huge amount of fund has been allocated to polio immunizations in Pakistan. The global polio eradication initiative is focusing to reach to every single individual. If the polio is eradicated globally, so after smallpox it would only be the $2^{\text {nd }}$ time in human history that a disease is eradicated. Since 1988 , development and effective vaccines coverage resulted in $99.9 \%$ reduction of polio cases worldwide. In 1988, an estimated 350,000 wild polio cases were reported. Since, then the number has fallen significantly and in 2018, only 33 wild polio cases were reported from polio endemic countries (21 in Afghanistan, 12 in Pakistan, and 0 in Nigeria). In addition, the total number of circulating vaccine-derived poliovirus 
(cVDPV) were 103 in 2018, of which 69 cases reported in non-endemic countries while the remaining 34 cases were reported in Nigeria ${ }^{3}$.

Pakistan is one of the polio endemic countries due to regular intervals of polio workers insecurity and parental refusal from vaccination pushed the country far to achieve global polio eradication movement. In March 2015, an estimated (79\%) children in Pakistan were vaccinated. Of the total targeted children, 33,695 $(<1 \%)$ children were missed due to parent's misunderstanding and refusal. On other hand, $(20 \%)$ cases were missed due to security issues in the country ${ }^{4}$. The Federally Administered Tribal Areas (FATA) were under the control of militant groups (Taliban). These militants not only imposed ban on polio immunization but also attacked many polio workers. As a result, polio immunization has not been undertaken and many of children were left unvaccinated ${ }^{5}$. Due to this gap, in 2014 majority of the reported cases of polio were from FATA and neighboring province of Khyber Pakhtunkhwa (KP) ${ }^{6}$.

In order to beat these militants, security forces launched an operation. As a consequence, an estimated 1 million people from un-vaccinated area were migrated to different parts of the country. Among these internally displaced people (IDP), some were carried the polio virus that was transmitted in different areas of Pakistan. Pakistan has made substantial progress towards polio eradication but the game is not over yet. The statistics showed that after the significant decline in number of polio cases from 307 in 2014 to only 12 cases in 2018, the government was hoping the eradication of polio from the country but unfortunately once again the battle won by the virus and in 2019 , the number of polio cases has increased with an alarming rate ${ }^{7}$.

In 2019, a total of 117 wild poliovirus type 1 (WPV1) cases have been reported in Pakistan. However, highest number of cases $(n=92)$ were from KP. In addition, a total of cVDPV2 cases $(n=18)$ were reported in the country (Table 1$)^{8}$. Data showed that the disease is still endemic in rural and remote areas of KP which is an alarming threat for global polio eradication.

The global polio eradication movement is almost near to the finishing line but some of the anti-polio agents in Pakistan are badly affecting this campaign. Once again, the current polio vaccination campaign $\left(22^{\text {nd }}\right.$ to $24^{\text {th }}$ April 2019) has been accused by the local community and anti-polio forces in the country by imposing a ban on the polio vaccination and spreading of conspiracy theories and rumors. This happened in Peshawar, the capital city of KP. The FATA and KP have been declared as the "Hub of polio" in Pakistan as shown in Figure 1. This created a panic in the common population of KP province as well as in other parts of the country. As a result, most of the people refused to vaccinate their children ${ }^{9}$.

In every polio vaccination campaign more than 40,000 parents refuse to administer vaccine to their children in Pakistan ${ }^{10}$. During the past and the recent gunning down of polio workers has seen the polio vaccination campaign take a major setback and failure to contain. Previous studies showed that the polio vaccination coverage is far below than that required for eradication ${ }^{11}$. During the recent polio campaign, two polio workers were attacked (one get expired and other was seriously injured) in Chaman, Balochistan, Pakistan which leads to stop polio vaccination campaign $^{12}$.

The polio vaccination accused might be one of the key risk factor in spreading of polio disease. In the past, India had also faced the polio vaccination refusal by certain communities. Because of the organized efforts and effective managements of government health institutions, media also played a tremendous role to achieve the targeted milestone and successfully eradicated polio ${ }^{13}$. A huge responsibility lies on the government and health authorities of polio endemic countries to ensure the safe vaccination campaign to eradicate the disease. It can be achieved by strengthen the coordination between local health authorities, community workers and non-governmental organizations.

It is predicted that if the immunization campaign get disturbed on regular intervals, the number of cases may significantly increase and the dream of polio eradication from Pakistan will not come true. One of the major obstacles in polio eradication is the worse perception of parents about polio immunization (especially in the high zone areas like KP, FATA and Karachi). It is the perception of common people that polio vaccine leads to infertility as well as this vaccine cause polio instead of treating it. To change the misconceptions of parents and local community, evidence-based approaches and strategies need to be adopted. Previous published studies showed that poor knowledge about polio immunization, religious beliefs and negative attitudes of participants are the major barriers towards polio immunization ${ }^{14}$.

Strict actions and effective policies are needed to implement on emergency basis by launching community awareness program about polio immunizations. It will be very helpful to involve all the stakes holders of the society, specially the religious leaders and scholars to whom masses follow allot. Strong surveillance network and polio workers safety can make the polio vaccination campaign effective. 


\begin{tabular}{|c|c|c|c|c|c|c|c|c|c|c|c|c|}
\hline \multicolumn{6}{|c|}{ Province/region } & \multicolumn{6}{|c|}{ WPV polio cases } & \multirow{2}{*}{$\begin{array}{c}\text { cVDPV2 } \\
2019\end{array}$} \\
\hline & 2010 & 2011 & 2012 & 2013 & 2014 & 2015 & 2016 & 2017 & 2018 & 2019 & Total & \\
\hline Punjab & 7 & 9 & 2 & 7 & 5 & 2 & 0 & 1 & 0 & 8 & 41 & 2 \\
\hline Sindh & 27 & 33 & 4 & 10 & 30 & 12 & 8 & 2 & 1 & 6 & 152 & 0 \\
\hline $\mathrm{KP}^{*}$ & 98 & 82 & 47 & 76 & 247 & 33 & 10 & 1 & 8 & 92 & 694 & 12 \\
\hline Balochistan & 12 & 73 & 4 & 0 & 25 & 7 & 2 & 3 & 3 & 11 & 140 & o \\
\hline GB & 0 & 1 & 1 & 0 & 0 & 0 & 0 & 1 & 0 & 0 & 3 & 4 \\
\hline AJK & 0 & 0 & 0 & 0 & 0 & 0 & 0 & 0 & 0 & 0 & 0 & 0 \\
\hline Total & 144 & 198 & 58 & 93 & 307 & 54 & 20 & 8 & 12 & 117 & 1030 & 18 \\
\hline
\end{tabular}

Note: KP*: (Khyber Pakhtunkhwa, Federal Administrated Tribal Area and Khyber Pakhtunkhwa Provincial Districts); GB: Gilgit-Baltistan; AJK: Azad Jammu and Kashmir.

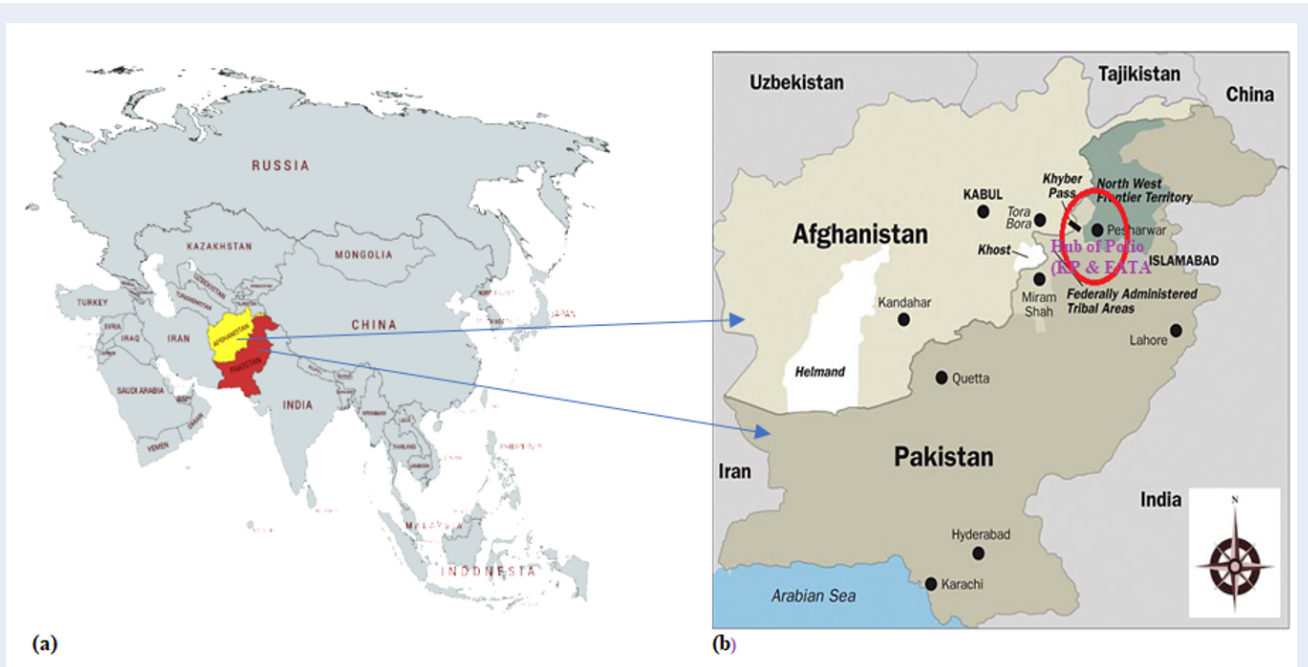

Figure 1: a) Map of Asia; b) Map of Pakistan and Afghanistan. The red circle represents polio hub in Pakistan.

\section{FINAL REMARKS}

Within the last few years, effective vaccine delivery, militants' attacks and parental refusal from vaccination remained the key challenges to fight against polio in Pakistan. So far in 2019, majority of the new cases were reported in KP. It may be due to polio immunization program has been accused in the region. Moreover, Pakistan and Afghanistan share a long border which is located in this region. A repeatedly substantial population migration occurs between the both countries and significant cross-border activity keep on spreading the virus. In Pakistan, an estimated 1,400,000 Afghan people (refugees) are unregistered while the number of registered refugees are $1,543,556^{15}$.

The authorities prefer to facilitate the registered refugees first, sometime leaving some unregistered people un-vaccinated. Insecurity of polio workers is also associated with increased incidence of polio. Discrepancy theories about vaccines and literacy rate are correlated. Due to low literacy rate in KP, the awareness about polio is low. To reach at zero polio case, some basic strategies need to be adopted particularly in the high-risk zones of the country. By tackling the misconception of parents against vaccinations, retaining public trust, improving coordination between government and non-government organizations and health institutes, community engagement and mobilization, ensuring normal vaccine supply to the rural and remote areas, strengthening the routine immunization infrastructure, adequate financing and polio workers safety may lead to eradicate the polio from the country. 


\section{CONCLUSIONS}

In Pakistan during the past and the recent gunning down of polio workers and parental refusal has seen which resulted setback and failure of polio eradication. This might be one of the reasons of current polio outbreak in the country. Both the countries, Afghanistan and Pakistan must work together to stop the polio for good, with an effective strategies and an emphasis on high-quality immunization activities and disease surveillance to fulfill the remaining immunity missing gaps.

\section{ABBREVIATIONS}

AJK: Azad Jammu and Kashmir

cVDPV: Circulating Vaccine-derived Poliovirus

FATA: Federally Administered Tribal Areas

GB: Gilgit-Baltistan

IDP: Internally Displaced People

IPV: Inactivated Polio Vaccine

KP: Khyber Pakhtunkhwa

WHO: World Health Organization

WPV1: Wild Poliovirus Type 1

\section{COMPETING INTEREST}

The authors declared no conflicts of interest.

\section{AUTHOR'S CONTRIBUTIONS}

TA: Designed the study, collected the data and wrote the manuscript. H: Helped in writing. MK, THM, $\mathrm{MB}, \mathrm{FN}$ and JH: Edited and reviewed the manuscript. TA: Supervised the study.

\section{REFERENCES}

1. Centers for Disease Control and Prevention. Epidemiology and Prevention of Vaccine Preventable Diseases, 13th Edition; 2015. Available from: https://www.cdc.gov/vaccines/ pubs/pinkbook/downloads/polio.pdf.

2. World Health Organization. Poliomyelitis, Updated 9 February 2017. Available from: https://www.who.int/immunization/ diseases/poliomyelitis/en/.
3. KFF Henry J Kaiser Family Foundation. The U.S. Government and Global Polio Efforts|Fact Sheet. Henry J Kaiser Family Foundation, Washington DC, USA; 2019. Available from: http://files.kff.org/attachment/the-u-s-government-andglobal-polio-efforts-fact-sheet.

4. Ahmed I. Pakistan battles polio-and citizens' mistrust. The Tribune Review; 2015.

5. The lancet. Global polio eradication: not there yet. Lancet. 2013;381:1. Available from: https://doi.org/10.1016/S01406736(13)60002-1.

6. World Health Organization. Weekly AFP surveillance update Pakistan week 49. Islamabad, Pakistan: National Surveillance Cell Federal EPI, WHO Regional Office; 2014. Available from: https://reliefweb.int/sites/reliefweb.int/files/resources/ Week_49_Dec_06_2014.pdf.

7. Pakistan Today. Polio on the rise, updated 9 September, 2019. Available from: https://www.pakistantoday.com.pk/2019/09/ 09/polio-on-the-rise/.

8. Pakistan Polio Eradication Programme. Polio Cases in Provinces. Available from: https://www.endpolio.com.pk/ polioin-pakistan/polio-cases-in-provinces.

9. Ahmad T, Khan M, Musa T, Jin H. Polio vaccination campaign in Pakistan: A step towards eradication or still a challenge in hand? Human Vaccines \& Immunotherapeutics. 2020; [Online ahead of print]. PMID: 32208950. Available from: https://doi. org/10.1080/21645515.2020.1717152.

10. Ashfaq Y. New strategy unlikely to curtail refusal against antipolio vaccine. The DAWN News; 2014. Available from: http: //www.dawn.com/news/1154018.

11. Naeem M, Adil M, Abbas SH, Khan MZ, Naz SM, Khan A, et al. Coverage and causes of missed oral polio vaccine in urban and rural areas of Peshawar. J Ayub Med Coll Abbottabad. 2011;23:98-102.

12. Zafar M. Polio worker martyred in Chaman. The Express Tribune; 2019. Available from: https://tribune.com.pk/story/ 1959088/1-polio-worker-martyred-balochistan-attack/.

13. Bhaumik S. Polio eradication: Current status and challenges. Journal of Family Medicine and Primary Care. 2012;1(2):8485. PMID: 24479012. Available from: https://doi.org/10.4103/ 2249-4863.104936.

14. Khan M, Ahmad A, Aqeel T, Salman S, Ibrahim Q, Idrees J, et al. Knowledge, attitudes and perceptions towards polio immunization among residents of two highly affected regions of Pakistan. BMC Public Health. 2015;15:1100. PMID: 26541976. Available from: https://doi.org/10.1186/s12889-015-2471-1.

15. Majidi N, van der Vorst V, Foulkes C. Seeking safety, jobs, and more: Afghanistan's mixed flows test migration policies. Migration Policy Institute; 2016. Available from: http://www.migrationpolicy.org/article/seeking-safetyjobs-andmoreafghanistan $\%$ e2\%80\%99s-mixed-flows-testmigration-policies. 